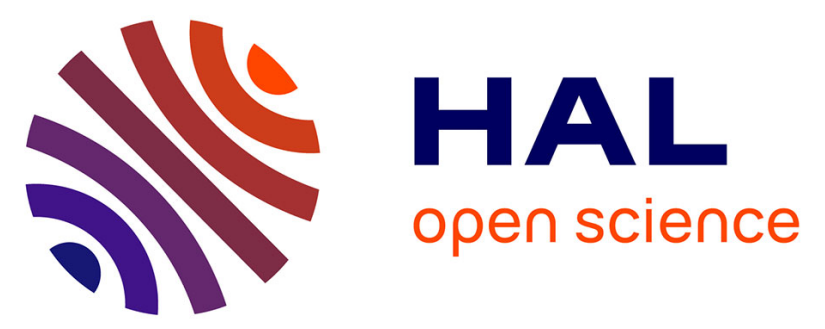

\title{
Evaluating the Implementation of a Fuzzy Logic System for Hybrid Vehicles as Alternative to Combustion Engine Buses in Big Cities
}

\author{
Emerson R. Abraham, Sivanilza T. Machado, Helton O. Silva, Carla C. Parizi, \\ João M. Reis, Helcio Raymundo, Pedro Costa Neto, Oduvaldo Vendrametto, \\ Marcos O. Morais, Antônio S. Brejão, et al.
}

\section{To cite this version:}

Emerson R. Abraham, Sivanilza T. Machado, Helton O. Silva, Carla C. Parizi, João M. Reis, et al.. Evaluating the Implementation of a Fuzzy Logic System for Hybrid Vehicles as Alternative to Combustion Engine Buses in Big Cities. IFIP International Conference on Advances in Production Management Systems (APMS), Sep 2015, Tokyo, Japan. pp.251-258, 10.1007/978-3-319-22756-6_31 . hal-01417485

\author{
HAL Id: hal-01417485 \\ https://hal.science/hal-01417485
}

Submitted on 15 Dec 2016

HAL is a multi-disciplinary open access archive for the deposit and dissemination of scientific research documents, whether they are published or not. The documents may come from teaching and research institutions in France or abroad, or from public or private research centers.
L'archive ouverte pluridisciplinaire HAL, est destinée au dépôt et à la diffusion de documents scientifiques de niveau recherche, publiés ou non, émanant des établissements d'enseignement et de recherche français ou étrangers, des laboratoires publics ou privés. 


\title{
Evaluating the Implementation of a Fuzzy Logic System for Hybrid Vehicles as Alternative to Combustion Engine Buses in Big Cities
}

\author{
Emerson R. Abraham ${ }^{1 *}$, Sivanilza T. Machado ${ }^{1}$, Helton R. O. Silva ${ }^{1}$, Carla \\ C. Parizi ${ }^{1}$, João G. M. Reis ${ }^{1}$, Helcio Raymundo ${ }^{1}$, Pedro L. O. Costa Neto ${ }^{1}$, \\ Oduvaldo Vendrametto ${ }^{1}$, Marcos O. Morais ${ }^{1}$, Antônio S. Brejão ${ }^{1}$, and Cleber \\ W. Gomes ${ }^{2}$ \\ 1 Postgraduate Studies Program in Production Engineering \\ Dr. Bacelar 1212, 04026002 São Paulo, Brazil \\ ${ }^{2}$ Metodista University \\ Alfeu Tavares 149, 09641000 São Bernardo do Campo, Brazil. \\ ${ }^{*}$ Corresponding author: emerson_abraham@yahoo.com.br
}

\begin{abstract}
The public transportation in urban centers involve many challenges related to environment. One of these challenges is reduce air and noise pollution in big cities. In São Paulo, for instance, it is estimated that $98 \%$ of the transport are made using buses with combustion engine, which are responsible for greatest part of air and noise pollution. Therefore, it is necessary to develop studies that help change the public transport policies in major cities, favoring the use of electric and hybrid buses. Thus, this paper aims to simulate the use of hybrid bus with fuzzy logic applied to improve the efficiency of this type of system. We made six simulations with MATLABC software and Fuzzy Logic Toolbox, considering velocity, topography and battery status as input variables. The results showed an effective control of the fuzzy system, with the feasibility of combining this with others experts systems.
\end{abstract}

Keywords: Hybrid bus; Fuzzy logic; Public transportation; Sustainability; Simulation.

\section{Introduction}

The public transportation in urban centers has been a constant problem for the environment and public health. In Brazil, it has not been different. São Paulo, for example, is the largest city in the country with more than 11 million people and, despite the various strategies used by transportation companies to reduce the air pollution and noise emissions, the level is still high.

A solution to change this scenario was to develop the Ecofrota program by municipality of São Paulo. This program implemented in 2009, requires that all public transportion system in the city use renewable fuel until 2018, reducing the use of fossil fuels at least $10 \%$ per year [1]. 
Currently there are three technologies available to the public transportation in São Paulo: bus with conventional combustion engine, electric bus and hybrid bus (combustion plus electric).

Some researchers believe that the hybrid vehicle becomes an interesting alternative because conventional buses have the disadvantage of being highly polluting, while the pure electric vehicle has the disadvantage of having to continually recharge [2] and [3]. Therefore, a hybrid system may provide the benefits of electric power without abandon the combustion engines for some situations.

To establish the feasibility of adopting a hybrid system by the cities and public transportation companies, is necessary to ensure that hybrid buses can respond the same requirements provided by conventional buses. Hence, our study aims to simulate the adoption of a fuzzy logic system to control the hybrid bus and improve its efficiency.

The simulation could be made using different approaches, but we defined adopt the fuzzy logic method because it is an important tool to solve problems in different areas of knowledge and applications.

According to Li et al as the hybrid vehicle is nonlinear and multivariable, the fuzzy logic is more suitable for the energy management[4]. Moreover, Neffati et al demonstrated the efficiency of fuzzy logic applied to control hybrid electric vehicles comparing different methodologies. To solve problems in real time the fuzzy logic shows good results[5].

This work was realized using the city of São Paulo as reference. Thus, the data was collected with the São Paulo Transport Company that manage the public transportation systems, and with the company that provide the electric and hybrid systems for buses in operation in the city, the Eletrabus [1] and [6]. The simulation was made with MATLAB(C) software using the fuzzy logic mode.

\section{Hybrid Systems}

The hybrid technology uses the combination of two or more sources of energy to feeds the system[6] and [4].

The hybrid system discussed in this work is performed by a electric motor, where the energy comes from a diesel powered engine. In addition, the vehicle has a battery bank that complements the energy available to the electric motor when required; the diesel powered engine recharges the battery bank, that avoid the use of external recharging of batteries. The combustion engine is fixed in rotation, reaching a reduction of smoke emission in $90 \%$ [6]

A hybrid vehicle uses three different types of settings: Series, Parallel-Series and Parallel [3]. In the case of the Eletrabus, responsible for the project in São Paulo city, the hybrid buses follow the parallel configuration [6], Figure 1.

The advantage of using the parallel system is the flexibility, which allows the system to operate whether a problem occurs in the electric generator, control and inverter, battery bank or the electric motor [3]. 


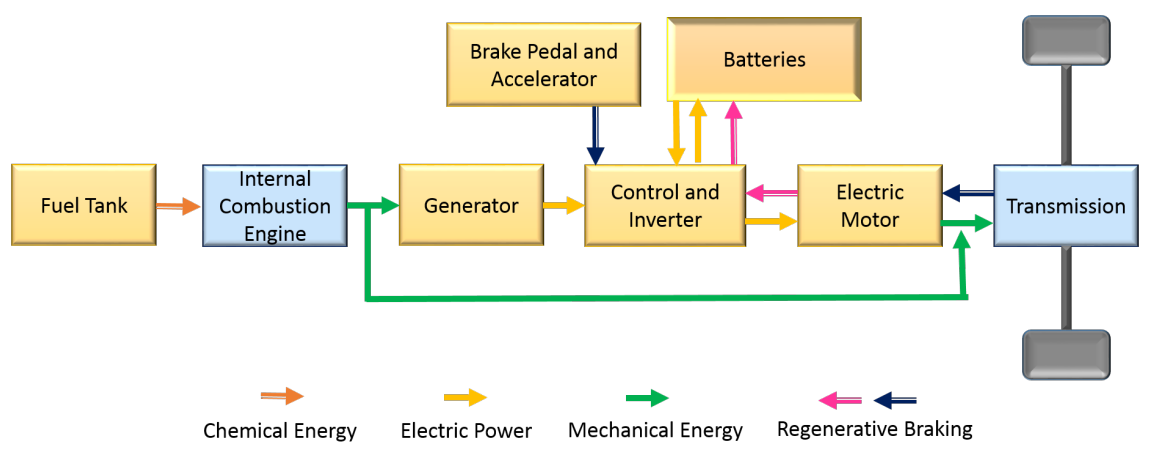

Fig. 1. Parallel Hybrid Vehicle. Source: Adapted from [6]

\section{$3 \quad$ Fuzzy Logic}

Fuzzy logic was developed by Lotfi A. Zadeh (1921-) in Berkeley in the 60s. This is a non classical kind of logic that allows intermediate values among False (0) and True (1) [7].

In the real world, there are variables that are vague or uncertain, impossible to be represented by classical logic. Fuzzy logic, enable to work with qualitative values and to infer from these quantitative values [8] and [9].

Zadeh states that there are two main reasons for the use of fuzzy logic, when the information available is too imprecise to justify the use of numbers, and when there is a tolerance for imprecision [8].

The applications of fuzzy logic in information systems began in the 80s. According to Zadeh, some of the first were made by F. L. Smidth to control cement kilns and the Sendai subway system designed by Hitachi[10].

\section{Methodology}

To answer the objective of this work three variables was considered: velocity, topography and battery status. Currently, Eletrabus uses a controller, as can be seen in Figure 1, which considers only velocity variable for swapping the system.[6]. We opted to include more variables for two reasons: (i) recommendation of fuzzy logic experts; and (ii) to create a more complex environment to test the potentially of the fuzzy system.

In this study, the main objective was to create a model with the knowledge of experts[9] and make simulations. The interaction of the model with the controller can be discussed in future works.

The fuzzy logic model depends of membership values and basic rules defined by experts. The Table 1 shows the membership values. 
Table 1. Membership values

\begin{tabular}{ccc}
\hline Variables 1 & Variables 2 & Variables 3 \\
\hline Velocity $($ Vel $)$ & Topography (Top) & BatteryStatus (Bat) \\
Slow $(\mathrm{S})(<20 \mathrm{~km} / \mathrm{h})$ & Declivity $(\mathrm{D})(<0$ degrees $)$ & Low $(\mathrm{L})(<72 \%)$ \\
Medium $(\mathrm{M})(18-37 \mathrm{~km} / \mathrm{h})$ & Plane $(\mathrm{P})(-2$ to 2 degrees $)$ & Medium $(\mathrm{M})(72 \%$ to $86 \%)$ \\
High $(\mathrm{H})(>35 \mathrm{~km} / \mathrm{h})$ & Acclivity $(\mathrm{A})(>0$ degree $)$ & High $(\mathrm{H})(>84 \%)$ \\
\hline
\end{tabular}

The next steps were to create 27 rules, each with a specific weight, which represents the possible combinations among the input variables. Applied conjunction (and) among the variables. The possible outputs are: "Batteries", "CombustionEngine" and "Not Applicable", where the last one reflects situations in which the relationship between the variables are not validated. The output values were defined on a scale ranging from 0 to 10 , Table 2 .

Table 2. Basic Rules

\begin{tabular}{|c|c|c|c|c|c|}
\hline \multicolumn{2}{|l|}{$\mathrm{N}$} & \multicolumn{2}{|c|}{ Input } & \multirow{2}{*}{$\begin{array}{c}\text { Output } \\
\text { Batteries }\end{array}$} & \multirow{2}{*}{$\begin{array}{c}\text { Weight } \\
0.5\end{array}$} \\
\hline 1 & Vel S and Top D & and & Bat $\mathrm{H}=$ & & \\
\hline 2 & Vel M and Top D & and & Bat $\mathrm{H}=$ & Not applicable & - \\
\hline 3 & Vel H and Top D & and & Bat $\mathrm{H}=$ & Not applicable & - \\
\hline 4 & Vel S and Top P & and & Bat $\mathrm{H}=$ & Batteries & 0.75 \\
\hline 5 & Vel M and Top P & and & Bat $\mathrm{H}=$ & Not applicable & - \\
\hline 6 & Vel $\mathrm{H}$ and Top $\mathrm{P}$ & and & Bat $\mathrm{H}=$ & Not applicable & - \\
\hline 7 & Vel S and Top A & and & Bat $\mathrm{H}=$ & Batteries & 1 \\
\hline 8 & Vel M and Top A & and & Bat $\mathrm{H}=$ & Not applicable & - \\
\hline 9 & Vel H and Top A & and & Bat $\mathrm{H}=$ & Not applicable & - \\
\hline 10 & Vel S and Top D & and & Bat $\mathrm{M}=$ & Batter & 0.5 \\
\hline & Vel M and Top D & and & Bat $\mathrm{M}=$ & Not applicable & - \\
\hline 12 & Vel H and Top D & and & Bat $\mathrm{M}=$ & Not applicable & - \\
\hline & Vel S and Top P & and & Bat $\mathrm{M}=$ & Batteries & 0.75 \\
\hline & Vel M and Top P & and & Bat $\mathrm{M}=$ & Not applicable & - \\
\hline & Vel $\mathrm{H}$ and Top $\mathrm{P}$ & and & Bat $\mathrm{M}=$ & Not applicable & - \\
\hline & Vel S and Top A & and & Bat $\mathrm{M}=$ & Batteries & 1 \\
\hline & Vel $\mathrm{M}$ and Top A & and & Bat $\mathrm{M}=$ & Not applicable & - \\
\hline & Vel H and Top A & and & Bat $\mathrm{M}=$ & Not applicable & - \\
\hline & Vel S and Top D & and & Bat $\mathrm{L}=$ & Not applicable & - \\
\hline & Vel $M$ and Top D & and & Bat $\mathrm{L}=\mathrm{C}$ & CombustionEngine & 0.5 \\
\hline & Vel H and Top D & and & Bat $\mathrm{L}=\mathrm{C}$ & CombustionEngine & 0.5 \\
\hline & Vel S and Top P & and & Bat $\mathrm{L}=$ & Not applicable & - \\
\hline & Vel M and Top P & and & Bat $\mathrm{L}=$ & CombustionEngine & 0.75 \\
\hline & Vel $\mathrm{H}$ and Top $\mathrm{P}$ & and & Bat $L=$ & CombustionEngine & 0.75 \\
\hline & Vel S and Top A & and & Bat $\mathrm{L}=$ & Not applicable & - \\
\hline & Vel $M$ and Top A & and & Bat $\mathrm{L}=\mathrm{C}$ & CombustionEngine & 1 \\
\hline & Vel $\mathrm{H}$ and Top A & and & Bat $\mathrm{L}=\mathrm{C}$ & CombustionEngine & 1 \\
\hline
\end{tabular}


To build the basic rules in MATLABC), 12 of the 27 combinations were added, where 15 combinations resulting in "Not applicable" were not added because in these cases the actual results are the same value for both "Batteries" and "CombustionEngine". The composition of the inference engine with the input variables, the rules (Hybrid Engine) using Mamdani method, and the output variables using the method (SOM), can be seen in Figure 2.

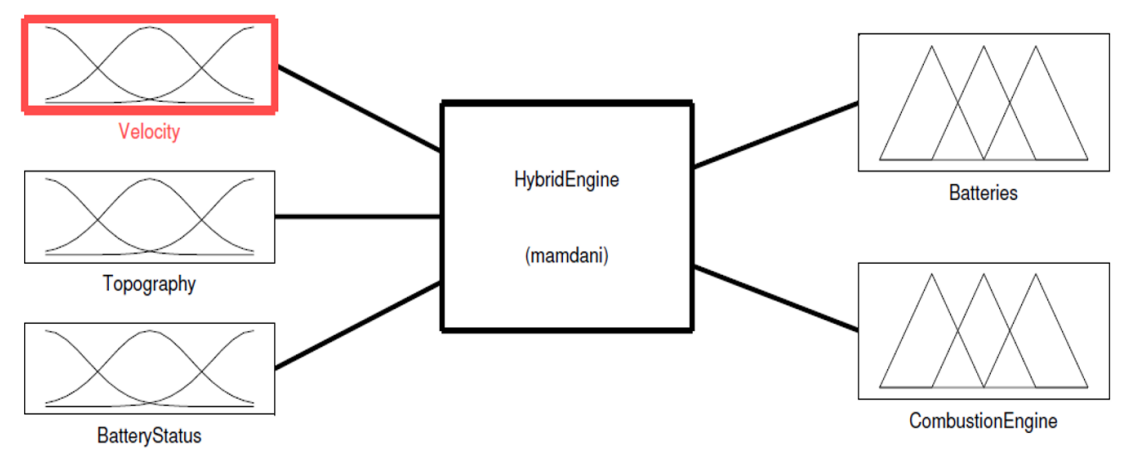

Fig. 2. Inference Engine MATLABC)

After the construction of the model, we made six simulations on MATLABC R2014a with addition of the Fuzzy Logic Toolbox: five simulations with data within the specified range of values that meet any of the 12 rules defined in MATLABC), and 1 simulation based on data within the set of values that do not meet any of the 12 rules defined in MATLABCC. Each simulation produce a representation of the results such as performed in Figure 3.
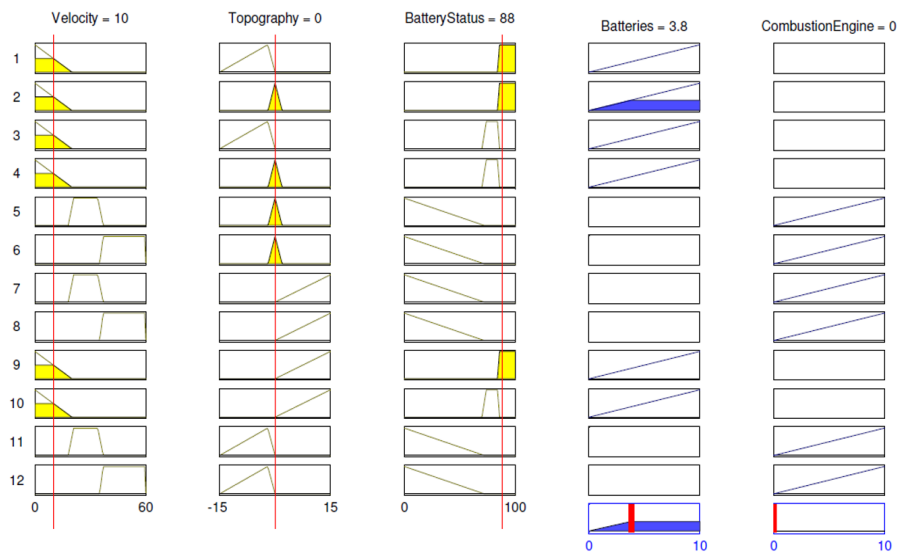

Fig. 3. Graphic Resulted from MATLAB@ Simulations 
The analysis presented in the results and discussion section are performed using the graphic resulted of the fuzzy logic simulation.

\section{Results and Discussion}

The results of these inferences indicate a degree of priority for Batteries or Combustion Engine, ranging from 0 to 10. The use of Mamdani and SOM methods in defuzzification brought the lowest possible results for the simulations.

The allocation of specific weights for each rule, demonstrated a more detailed control of inference. The system performance is effected by the input variables settings and the basic rules that can be refined [11]

For the first simulation, the values attributed were 10 for Velocity, 0 for Topography and 88 for BatteryStatus presented low speed, topography plan and high battery charge (rule 4) in Table 2. According to this rule, the lower the speed, the flatter the terrain and the higher battery load, increase the expectation of minimum result. The value found was 3.8 that indicates the minimum priority of batteries.

For the second simulation, the values attibuted were 7 for Velocity, -12 for Topography and 76 for BatteryStatus and showed low speed, slope topography and average battery life (rule 10) in Table 2. According to this rule, the lower the speed, the lower the slope of the land and the higher battery load, increase the expectation of minimum results. The value of 1.2 is the minimum priority of batteries. In this case, the slope of the terrain in 12 degrees affected the result to a low value. This result is consistent, because the weight of the vehicle and the inclination uses the gravity, requiring fewer batteries.

For the third simulation, the values attributed were 58 for Velocity, 1.2 for Topography and 22 for BatteryStatus, considering the high speed, flat topography and low battery (rule 24) in Table 2 . The flatter the terrain and the lower the battery load, increase the expectation of minimum results. The variation at high speed does not affect the result in most value ranges. The value of 2.8 is the minimum priority of the combustion engine.

For the fourth simulation the values attributed were 25 for Velocity, 11 for Topography and 32 for BatteryStatus, which relates to the average speed, slope topography and low battery (rule 26) in Table 2. The flatter the terrain and the lower the battery load, increase the expectation of minimum results. The variation in the average speed does not greatly effect the outcome in most ranges of values. The value of 5.6 is the minimum priority of the combustion engine.

For the fifth simulation the values attributed were 55 for Velocity, 12 for Topography and 22 for BatteryStatus, with high speed, slope topography and low battery (rule 27) in Table 2 . The greater the slope of the land, and the lower the battery load, increase the expectation of minimum results. The variation at high speed does not effect the result in most ranges of values. The value of 7 is the minimum priority of the combustion engine; it is consistent due to the slope of 12 degrees, which requires more combustion engine to suppress gravity. 
For the sixth simulation, the values attributed were: 55 for Velocity, 12 for Topography and 92 for BatteryStatus, considering the high speed, slope topography and high battery charge (rule 9) in Table 2 . This rule has not been allocated in the database for the simulation, since the combination of its variables are not applied; however the data may occur, which in this case returns the values of 5 for batteries and 5 for combustion engine.

For the 15 rules where the output value is "Not Applicable" rather than prioritize the combustion engine, the inference points to a neutral outcome, allowing other considerations for decision. Moreover, due to the limitations of the fuzzy control [12], these outputs could also be entered as input values to other fuzzy systems or expert systems, such as neural networks. For example, Barzegar et al. studied a hybrid adaptive model, based on a combination of coloured Petri nets, fuzzy logic and learning automata, to efficiently control traffic signals[13].

So, this results and discussions indicated the feasibility of applying the fuzzy logic to control hybrid vehicles.

\section{Conclusions and Outlook}

The simulation results performed an effective use of the system, apparently showing no flaws or inconsistencies. The system behaved properly according to the rules and the specified values. For the cases that resulted in neutral or equal, the hybrid system could use the combustion engine and batteries (both), or prioritize the use of one in function of other variables. As a suggestion, we recommend using the outputs that returned equal to 5 (sixth simulation) as input values to other systems and new simulations.

This work have presented some limitations, being thus for future works the next steps aim to use SIMULINK on MATLAB $\subset$ to demonstrate the behaviour of the fuzzy system proposed.

São Paulo like many big cities in the world are suffering with problems of gas and noise emissions and alternatives need to be finding out to reduce or solve these issues. Our studies have indicated the benefits of the use of hybrid systems in public transportation to reduce air pollution and noise emissions.

\section{References}

1. SPTRANS: Plano de controle de poluição veicular no município de São Paulo. Secretaria Municipal de Transportes SMT (2011)

2. Choi, H., Oh, I.: Analysis of product efficiency of hybrid vehicles and promotion policies. Energy Policy 38(5), 2262-2271 (2010)

3. Alipour, H., Asaei, B., Farivar, G.: Fuzzy Logic Based Power Management Strategy for Plug-in Hybrid Electric Vehicles with Parallel Configuration. In: Proceedings of the International Conference on Renewable Energies and Power Quality, Santiago de Compostela, Spain. pp. 28-30 (2012)

4. Li, Q., Chen, W., Li, Y., Liu, S., Huang, J.: Energy management strategy for fuel cell/battery/ultracapacitor hybrid vehicle based on fuzzy logic. International Journal of Electrical Power \& Energy Systems 43(1), 514-525 (2012) 
5. Neffati, A., Guemri, M., Caux, S., Fadel, M.: Energy management strategies for multi source systems. Electric Power Systems Research 102, 42-49 (2013)

6. ELETRABUS: Tecnologia dos Veículos híbridos (2013), http://www.eletrabus. com/hibrido.htm

7. Mendel, J.M.: Reflections on some important contributions made by Lotfi A. Zadeh that have impacted my own research. Scientia Iranica 18(3), 549-553 (2011)

8. Zadeh, L.A.: Fuzzy logic $=$ computing with words. IEEE Transactions on Fuzzy Systems 4(2), 103-111 (1996)

9. Rezende, S.O.: Sistemas inteligentes: fundamentos e aplicações. Editora Manole Ltda (2003)

10. Zadeh, L.A.: Fuzzy Logic, Neural Networks, and Soft Computing. Commun. ACM 37(3), 77-84 (1994)

11. Taha, M.A., Ibrahim, L.: Traffic Simulation System based on Fuzzy Logic. Procedia Computer Science 12, 356-360 (2012)

12. Zhou, Y., Ou, S., Lian, J., Li, L.: Optimization of Hybrid Electric Bus Driving System's Control Strategy. Procedia Engineering 15, 240-245 (2011)

13. Barzegar, S., Davoudpour, M., Meybodi, M.R., Sadeghian, A., Tirandazian, M.: Formalized learning automata with adaptive fuzzy coloured Petri net; an application specific to managing traffic signals. Scientia Iranica 18(3), 554-565 (2011) 